\title{
Karakteristik pasien dengan preeklampsia di RSUP Prof. Dr. R. D. Kandou Manado
}

\author{
${ }^{1}$ Rien A. Hutabarat \\ ${ }^{2}$ Eddy Suparman \\ ${ }^{3}$ Freddy Wagey
}

\author{
${ }^{1}$ Kandidat Skripsi Fakultas Kedokteran Universitas Sam Ratulangi Manado \\ ${ }^{2}$ Bagian Obstetri dan Ginekologi Fakultas Kedokteran Universitas Sam Ratulangi Manado \\ Email: rienhutabarat@gmail.com
}

\begin{abstract}
World Health Organization (WHO) estimates that 585.000 women die every day from complications of pregnancy, birth process, and as a result of unsafe abortion. Maternal mortality in Indonesia was 307 of 100.000 live births and the infant mortality in Indonesia was 39 of 1000 live births. The most frequent cause of maternal mortality and fetal mortality is preeclampsia. This was a retrospective descriptive study. Data were obtained from the medical records of preeclampsia patients from January 1 until December 31, 2013 at the Department of Obstetrics and Gynecology, Prof. Dr. R. D. Kandou Hospital Manado. The results showed that there were 135 patients diagnosed with preeclampsia. There were 79 patients (58.52\%) with mild preeclampsia, and 56 patients (41.48\%) with severe preeclampsia. The highest frequencies were found at the age group 21-35 years (in mild preeclampsia $67.1 \%$ and in severe preeclampsia $73.2 \%$ ); housewives (in mild preeclampsia $84.8 \%$ and in severe preeclampsia $78.5 \%$ ); senior high school education (in mild preeclampsia $68.36 \%$ and in severe preeclampsia $76.7 \%$ ); parity of multigravida (in mild preeclampsia $62 \%$ and in severe preeclampsia 59\%); and interval of labor 2-5 years (in mild preeclampsia $51.02 \%$ and in severe preeclampsia $52 \%)$.
\end{abstract}

Keywords: preeclampsia, characteristics

\begin{abstract}
Abstrak: World Health Organization (WHO) memperkirakan 585.000 perempuan meninggal setiap hari akibat komplikasi kehamilan, proses kelahiran, dan akibat aborsi yang tidak aman. Angka kematian ibu bersalin di Indonesia adalah 307 per 100.000 kelahiran hidup dan angka kematian bayi di Indonesia adalah 39 per 1000 kelahiran hidup. Salah satu penyebab morbiditas dan mortilitas ibu dan janin adalah Preeklamsia. Penelitian ini menggunakan metode deskriptif retrospektif dengan melihat data rekam medik pasien Preeklampsia periode 1 Januari - 31 Desember 2013 di Bagian Obstetri-Ginekologi. Hasil penelitian memperlihatkan 135 pasien dengan diagnosis preeklampsia, terdiri dari 79 (58,52\%) preeklampsia ringan (PER), dan 56 (41,48\%) preeklampsia berat (PEB). Kelompok umur tersering ialah 21-35 tahun (pada PER 67,1\% dan PEB 73,2\%). Pekerjaan tersering ialah ibu rumah tangga (pada PER 84,8\% dan PEB 78,5\%). Pendidikan tersering ialah SMA (pada PER 68,36\% dan PEB 76,7\%). Jumlah paritas tersering ialah multigravida (pada PER 62\% dan PEB 59\%). Jarak persalinan tersering antara 2-5 tahun ( pada PER 51,02\% dan PEB 52\%).
\end{abstract}

Kata kunci: preeklampsia, karakteristik

World Health Organization (WHO) memperkirakan 585.000 perempuan meninggal setiap hari akibat komplikasi kehamilan, proses kelahiran, dan akibat aborsi yang tidak aman. Sekitar satu perempuan meninggal setiap menit. ${ }^{1}$ Negara-negara di Asia, termasuk Indonesia adalah negara dimana warga 
perempuannya memiliki kemungkinan kematian ibu akibat persalinan dan komplikasi kehamilan sebesar 307 dari 100.000 kelahiran pada tahun 2003 dan sebesar 269 pada tahun 2008, angka ini masih jauh dari target MDG tahun 2015, yakni 125 perkelahiran hidup. ${ }^{2}$ Angka kematian ibu bersalin di Indonesia 307 per 100.000 kelahiran hidup, sedangkan angka kematian bayi di Indonesia 39 per 1000 kelahiran hidup (Biro pusat statistic, 2005). Salah satu penyebab morbiditas dan mortilitas ibu dan janin ialah preeklampsia. ${ }^{3}$

Preeklampsia didefinisikan sebagai timbulnya hipertensi di sertai dengan proteinuria pada umur kehamilan lebih dari 20 minggu atau segera setelah persalinan. ${ }^{4}$ Proteinuria merupakan penanda objektif, yang menujukkan kebocoran endotel yang luas, suatu ciri khas preeklamsia. ${ }^{5}$ Dari gejala-gejala klinik preeklampsia dapat dibagi menjadi preeklampsia ringan dan preeklampsia berat. ${ }^{6}$ Berbagai usaha telah dilakukan untuk membuktikan bahwa preeklampsia disebabkan oleh kelebihan sekresi plasenta atau hormone adrenal, tetapi bukti dasar hormonal tidak mencukupi. Teori lain yang lebih masuk akal adalah bahwa preeklampsia merupakan akibat dari beberapa macam autoimun atau alergi pada ibu yang disebabkan kehadiran fetus. Selain itu terdapat bukti bahwa preeklampsi diawali oleh insufisiensi suplai darah ke plasenta, yang mengakibatkan pelepasan substansi plasenta sehingga menyebabkan disfungsi endotel vascular ibu yang luas. ${ }^{7}$ Upaya menurunkan tingkat morbilitas dan mortalitas preeklampsia dilakukan dengan memberikan penanganan dini hingga melakukan pencegahan pada ibu hamil yang di anggap beresiko tinggi terjadinya preeklampsia. ${ }^{8}$ Melihat tingginya angka morbiditas dan mortalitas ibu dan bayi yang disebabkan oleh kejadian preeklampsia, maka peneliti tertarik melakukan penelitian untuk mengetahuai karakteristik pasien dengan preeklampsia di BLU RSUP Prof. Dr. R. D. Kandou Manado periode 1 Januari - 31 Desember 2013.

\section{METODE PENELITIAN}

Penelitian ini menggunakan metode deskriptif retrospektif dengan melihat data rekam medik pasien Preeklampsia periode 1 Januari - 31 Desember 2013 di Bagian Obstetri-Ginekologi. Subjek penelitian yaitu semua pasien yang didiagnosis dengan preeklampsia di bagian Obstetri Ginekologi BLU RSUP Dr. R. D. Kandou Manado.

\section{HASIL PENELITIAN}

Dari seluruh ibu yang didiagnosis dengan Preeklamsia di bagian Obstetri dan Ginekologi pada 1 Januari 2013 - 31 Desember 2013, subjek penelitian yang didapatkan berdasarkan kriteria inklusi berjumlah 135 orang dengan distribusi berdasarkan diagnosis preeklampsia ringan dan preeklampsia berat dapat dilihat pada Tabel.

Tabel 1 menunjukkan distribusi subjek penelitian berdasarklan klasifikasi preeklampsia dimana subjek didominasi oleh penderita preeklampsia ringan sebanyak 79 orang $(58,52 \%)$ dan penderita preeklampsia berat sebanyak 56 orang $(41,48 \%)$.

Tabel 1. Distribusi subjek penelitian berdasarkan klasifikasi preeklampsia

\begin{tabular}{lccc}
\hline Tahun & PER(\%) & PEB(\%) & Total \\
\hline 2013 & $79(58,52 \%)$ & $56(41,48 \%)$ & 135 \\
\hline
\end{tabular}

Tabel 2 menunjukkan distribusi subjek penelitian berdasarkan umur dimana hasil untuk penderita preeklampsia ringan didominasi oleh kelompok umur 21 - 35 tahun $(67,1 \%)$ dan untuk penderita preeklampsia berat pun didominasi kelompok umur 21 - 35 tahun (73,2\%).

Tabel 2. Distribusi subjek penelitian berdasarkan umur

\begin{tabular}{lcclr}
\hline \multirow{2}{*}{ Umur } & \multicolumn{2}{c}{$\mathrm{N}$} & \multicolumn{2}{c}{$\%$} \\
\cline { 2 - 5 } & PER & PEB & PER & PEB \\
\hline$<20$ tahun & 9 & 5 & $11,4 \%$ & $9 \%$ \\
$21-35$ tahun & 53 & 41 & $67,1 \%$ & $73,2 \%$ \\
$>35$ tahun & 17 & 10 & $21,5 \%$ & $17,8 \%$ \\
\hline Total & 79 & 56 & $100 \%$ & $100 \%$ \\
\hline
\end{tabular}

Tabel 3 menunjukkan distribusi subjek 
penelitian berdasarkan pekerjaan dimana hasil untuk penderita preeklampsia ringan didominasi oleh kelompok pekerjaan IRT sebanyak 67 orang $(84,8 \%)$ dan untuk penderita preeklampsia berat pun didominasi kelompok pekerjaan IRT sebanyak 44 orang (78,5\%).

Tabel 3. Distribusi Subjek Penelitian Berdasarkan Pekerjaan.

\begin{tabular}{lcrrr}
\hline \multirow{2}{*}{ Pekerjaan } & \multicolumn{2}{c}{$\mathrm{N}$} & \multicolumn{2}{c}{$\%$} \\
\cline { 2 - 5 } & PER & PEB & PER & PEB \\
\hline IRT & 67 & 44 & $84,8 \%$ & $78,5 \%$ \\
Pelajar & 3 & 4 & $3,79 \%$ & $7,14 \%$ \\
PNS & 6 & 5 & $7,59 \%$ & $8,92 \%$ \\
Wiraswasta & 3 & 3 & $3,79 \%$ & $5,35 \%$ \\
\hline Total & 79 & 56 & $100 \%$ & $100 \%$ \\
\hline
\end{tabular}

Tabel 4 menunjukkan distribusi subjek penelitian berdasarkan pendidikan dimana hasil untuk penderita preeklampsia ringan didominasi oleh kelompok pendidikan SMA sebanyak 54 orang $(68,4 \%)$ dan untuk penderita preeklampsia berat pun didominasi oleh kelompok SMA sebanyak 43 orang (76,7\%).

Tabel 4. Distribusi Subjek Penelitian Berdasarkan Pendidikan.

\begin{tabular}{lccrr}
\hline Pendidikan & \multicolumn{2}{c}{$\mathrm{N}$} & \multicolumn{2}{c}{$\%$} \\
\cline { 2 - 5 } & PER & PEB & \multicolumn{1}{c}{ PER } & PEB \\
\hline SD & 9 & 5 & $11,4 \%$ & $9 \%$ \\
SMP & 14 & 7 & $17,7 \%$ & $12,5 \%$ \\
SMA & 54 & 43 & $68,4 \%$ & $76,7 \%$ \\
S1 & 2 & 1 & $2,5 \%$ & $1,8 \%$ \\
\hline Total & 79 & 56 & $100 \%$ & $100 \%$ \\
\hline
\end{tabular}

Tabel 5 menunjukkan distribusi subjek penelitian berdasarkan jumlah paritas dimana hasil untuk penderita preeklampsia ringan didominasi oleh kelompok multigravida dan untuk penderita preeklampsia berat didominasi oleh kelompok multigravida

Tabel 5. Distribusi Subjek Penelitian Berdasarkan Jumlah Paritas

\begin{tabular}{llcrc}
\hline Paritas & \multicolumn{2}{c}{$\mathrm{N}$} & \multicolumn{2}{c}{$\%$} \\
\cline { 2 - 5 } & PER & PEB & PER & PEB \\
\hline Primigravida & 30 & 23 & $38 \%$ & $41 \%$ \\
Multigravida & 49 & 33 & $62 \%$ & $59 \%$ \\
\hline Total & 79 & 56 & $100 \%$ & $100 \%$ \\
\hline
\end{tabular}

Tabel 6 menunjukkan distribusi subjek penelitian berdasarkan jarak persalinan penderita preeklampsia yang telah diketahui merupakan wanita dengan multigravida dimana hasil untuk penderita preeklampsia ringan didominasi oleh kelompok jarak persalinan antara 2 - 5 tahun sebanyak 25 orang (51\%) dan untuk penderita preeklampsia berat pun didominasi oleh kelompok $2-5$ tahun sebanyak 17 orang (52\%).

Tabel 6. Distribusi Subjek penelitian berdasarkan Jarak persalinan.

\begin{tabular}{lccrr}
\hline Jarak Persalinan & \multicolumn{2}{c}{$\mathrm{N}$} & \multicolumn{2}{c}{$\%$} \\
\cline { 2 - 5 } & PER & PEB & PER & PEB \\
\hline$<2$ tahun & 1 & 1 & $2 \%$ & $3 \%$ \\
$2-5$ tahun & 25 & 17 & $51 \%$ & $52 \%$ \\
$>5$ tahun & 23 & 15 & $47 \%$ & $45 \%$ \\
\hline Total & 49 & 3 & $100 \%$ & $100 \%$ \\
\hline
\end{tabular}

\section{BAHASAN}

Penelitian yang dilakukan di RSUP Prof. DR. R. D. Kandou Manado dengan metode penelitian deskriptif rektrospektif dan mengambil data sekunder melalui data rekam medis pasien pada 1 januari - 31 Desember tahun 2013 menunjukkan bahwa berdasarkan hasil karakteristik pasien dengan preeklampsia lebih banyak ditemukan pasien dengan preeklampsia ringan yaitu sebanyak 76 orang $(56,3)$ dibandingkan pasien dengan preeklampsia berat yaitu 59 orang $(43,7)$ dari keseluruhan pasien yang didiagnosis dengan preeklampsia yaitu sebanyak 135 orang.

Hasil penelitian karakteristik pasien preeklampsia berdasarkan umur menunjukkan bahwa pasien dengan kelompok umur 21-35 tahun lebih mendominasi baik pada pasien preeklampsia ringan sebanyak 53 orang $(67,1 \%)$ dan pada preeklampsia berat sebanyak 41 orang $(73,2)$. Hal ini sesuai dengan hasil penelitian yang di lakukan pada tahun 2010 oleh Estina V C ${ }^{1}$ dimana dapat disimpulkan kejadian preeklamsia tersering pada kelompok umur yang termasuk usia produktif untuk merencanakan kehamilan.

Hasil penelitian karakteristik pasien preeklampsia berdasarkan pendidikan menunjukkan bahwa pasien dengan 
kelompok pendidikan terbanyak adalah kelompok pendidikan SMA dengan jumlah pada preeklampsia ringan sebanyak 54 orang $(68,36 \%)$ dan pada preeklampsia berat 43 orang (76,7\%). Banyaknya pasien yang berpendidikan SMA seiring dengan kesadaran akan pentingnya pendidikan. Pendidikan secara tidak langsung berpengaruh dalam menentukan dan mengambil sebuah keputusan. Tingginya tingkat pendidikan seorang wanita diharapkan semakin meningkat juga pengetahuan dalam mengantisipasi kesulitan kehamilan dan persalinan sehingga termotivasi untuk melakukan pengawasan kehamilan secara teratur. Namun, pendidikan yang dimiliki oleh seseorang belum menjamin untuk menderita atau tidak menderitanya seseorag tersebut pada suatu penyakit tertentu, hasil ini sesuai dengan hasil penelitian dari Nuryani(2013). ${ }^{9}$

Dari hasil penelitian karakteritik pasien preeklampsia berdasakan pekerjaan, hasil penelitian ini sesuai dengan hasil penelitian yang di lakukan pada tahun 2013 oleh Wahyuni Silomba, yang menyebutkan bahwa ibu hamil yang tidak bekerja (ibu rumah tangga) mengalami preeklampsia ringan 55,3\% dan preeklampsia berat $52,4 \% .{ }^{8}$ Begitu pula dengan hasil penelitian ini didapatkan ibu yang berprofesi sebagai ibu rumah tangga yang merupakan kelompok pekerjaan nonformal mengalami preeklampsia terbanyak yaitu untuk pasien preeklampsia ringan sebanyak 67 orang $(84,8 \%)$ dan pada preeklampsia berat sebanyak 44 orang (78,5\%).

Hasil penelitian karakteristik pasien preeklampsia berdasarkan jumlah paritas menunjukkan bahwa pasien dengan kelompok jumlah paritas terbanyak adalah multigravida dengan jumlah pada preeklampsia ringan sebanyak 49 orang (62\%) dan pada preeklampsia berat 33 orang (59\%). Hasil penelitian ini tidak sesuai dengan hasil penelitian yang di lakukan pada tahun 2010 oleh Estina V C yang menyakatan penderita preeklampsia tertinggi pada kelompok primigravida $(49,2 \%)^{1}$
Hasil penelitian karakteristik pasien preeklampsia berdasarkan jarak persalinan penderita preeklampsia yang telah diketahui merupakan wanita dengan status multigravida dimana hasil untuk penderita preeklampsia ringan didominasi oleh kelompok jarak persalinan antara $2-5$ tahun sebanyak 24 orang (50\%) dan untuk penderita preeklampsia berat di dominasi oleh kelompok $2-5$ tahun sebanyak 18 orang (52,94\%). Hasil penelitian ini sesuai dengan hasil penelitian $\operatorname{Nuryani(2013)^{9}}$ yang mencari hubungan antara jarak persalinan $<2$ tahun dengan kejadian preeklampsia dimana pada penelitian tersebut para peneliti mendapatkan hasil tidak berhubungan dan hasil tersebut sesuai dengan hasil penelitian ini dimana hasil penelitian ini menunjukkan penderita preeklampsia didapatkan pada jarak persalinan 2 - 5 tahun bukanlah pada jarak persalinan $<2$ tahun.

\section{SIMPULAN}

Dari hasil penelitian dan bahasan dapat disimpulkan bahwa di Bagian Obstetri Ginekologi BLU RSUP Dr. R. D. Kandou Manado pada tahun 2013:

a. Penderita preeklampsia terbanyak dengan klasifikasi preeklampsia ringan.

b. Kejadian preeklampsia mayoritas terjadi pada kelompok umur 21 - 35 tahun.

a. Kejadian preeklampsia mayoritas terjadi pada kelompok pekerjaan ibu rumah tangga.

b. Kejadian preeklampsia mayoritas terjadi pada kelompok pendidikan SMA.

c. Kejadian preeklampsia mayoritas terjadi pada kelompok jumlah paritas Multigravida.

d. Kejadian preeklampsia mayoritas terjadi pada kelompok Multigravida dengan jarak persalinan antara $2-5$ tahun.

\section{SARAN}

Bagi Peneliti diharapkan dapat memperbanyak pengetahuan dan informasi 
khususnya tentang preeklampsia sehingga bisa memberikan informasi tersebut secara langsung kepada masyarakat pada saat bekerja di masyarakat.

Bagi Institusi Pendidikan diharapkan untuk lebih memperbanyak referensi / buku - buku tentang ibu hamil terutama referensi tentang preeclampsia.

Bagi Institusi Pelayanan diharapkan dapat memberikan penyuluhan terhadap masyarakat tentang preeklampsia dan faktor-faktor yang bisa menjadi predisposisi terjadinya preeklampsia, juga pemeriksaan antenatal yang rutin bagi ibu hamil untuk mendeteksi dini terjadinya preeklampsia agar dapat mengurangi angka kejadian preeklampsia di masyarakat.

\section{DAFTAR PUSTAKA}

1. Estina V C, Delima E R, Gunanegara R F. Karakteristik Penderita Preeklamsi dan Eklamsi yang Dirawat Inap di Rumah Sakit Immanuel Bandung Periode Tahun 2006 - 2008. JKM. 2010;9:150-54.

2.Felicia D, Fredy FC, Iskanda W J. Suplementasi asam folat sebagai upaya pencegahan preeklamsia pada ibu hamil di Indonesia. Jurnal Ilmiah Mahasiswa Kedokteran Indonesia. 2010;1:30-35.

3. Faizah B R, Yanti. Hubungan Karakteristik ibu dengan kejadian Pre-eklamsia di RSUI YAKSSI Sragen. Jurnal Kebidanan. 2011;3;1-8.

4.Fauziyah Y. Obstetri Patologi. Yogyakarta: Nuha medika; 2012 p. 17-34.

5.Cunningham, Leveno, Blom, Hauth, Rouse, Spong. Hipertensi dalam Kehamilan. In: Obstetri Williams (23rd ed). Jakarta: EGC, 2005; p.741

6.Angsar MD. Hipertensi dalam kehamilan. In: Saifudin A,B editor. Ilmu kebidanan (4th ed). Jakarta: Bina Pustaka Sarwono Prawirohardjo, 2010; p.542

7.Guyton AC, Hall JE. Buku ajar Fisiologi Kedokteran (11th ed). Irawati et al. translator; Rachman YL, editor. Jakarta: EGC, 2007; p. 1089.

8.Silomba W. Karakteristik dan Luran Preeklampsi di RSUP Prof. Dr. R. D. Kandou Manado Periode 2011. Jurnal e-Biomedik(eBM). 2013:1;76-80 [cited 2014 Sep 17]. Available from: https://ejournal.unsrat.ac.id/index.php /ebiomedik/article/view/1166.

\section{Nuryani, Maghfirah A A,} Citrakesumasari, Alharini S. Hubungan pola makan, social ekonomi, antenatal care dan karakteristik ibu hamil dengan kasus preeklampsia di kota makassar. Media Gizi Masyarakat Indonesia. 2013:2:104-12. 